\title{
Effect of different tryptophan sources on amino acids availability to the brain and mood in healthy volunteers
}

\author{
C. Rob Markus • Christine Firk • Cindy Gerhardt • \\ Joris Kloek • GertJan F. Smolders
}

Received: 23 April 2008 / Accepted: 23 June 2008 / Published online: 23 July 2008

(C) The Author(s) 2008

\begin{abstract}
Rationale Reduced brain serotonin function is acknowledged as a vulnerability factor for affective disturbances. Since the production of serotonin is limited by the availability of its plasma dietary amino acid precursor tryptophan (TRP), the beneficial effects of tryptophan-rich alpha-lactalbumin whey protein (ALAC) have recently been studied. The effects of ALAC remain rather modest, and alternative protein sources of tryptophan may be more effective.

Objectives We tested whether hydrolyzed protein (HPROT) has greater effects on the plasma TRP/large neutral amino acids (LNAA) ratio and mood than intact ALAC protein in healthy volunteers.

Materials and methods In a double-blind, randomized cross-over study, plasma amino acids and mood were repeatedly measured in 18 healthy subjects before and after intake of ALAC and HPROT as well as after placebo protein, pure tryptophan, and a tryptophan-containing synthetic peptide. Except for the placebo protein, all interventions contained $0.8 \mathrm{~g}$ TRP.

Results Significantly faster and greater increases in plasma TRP/LNAA were found after HPROT than after ALAC. In
\end{abstract}

C. R. Markus $(\bowtie)$

Department of Neuropsychology and Psychopharmacology,

Faculty of Psychology, Maastricht University,

Room 3.773, Universiteitssingel 40,

6229 ER Maastricht, The Netherlands

e-mail: r.markus@psychology.unimaas.nl

C. R. Markus $\cdot$ C. Firk

Department of Clinical Psychological Science,

Maastricht University,

Maastricht, The Netherlands

C. Gerhardt · J. Kloek $\cdot$ G. F. Smolders

DSM Food Specialties B.V.,

Delft, The Netherlands addition, the effects of HPROT on plasma TRP/LNAA were comparable with the effects of the tryptophan-containing synthetic peptide and even exceeded the effect of pure tryptophan. Sixty minutes after intake, mood was improved only following intake of HPROT and pure tryptophan, whereas longer-lasting mood effects were only found after intake of HPROT.

Conclusions The use of a tryptophan-rich hydrolyzed protein source may be more adequate to increase brain tryptophan and 5-HT function compared with intact alphalactalbumin protein or pure tryptophan.

Keywords Tryptophan · Serotonin · Protein - Hydrolysate . Alpha-lactalbumin $\cdot$ Amino acids $\cdot$ Mood

\section{Introduction}

Brain serotonin (5-HT) receptors are widely distributed in the central nervous system and involve the regulation of several essential behavioral and physiological functions (e.g., mood, sleep, appetite, sexual behavior). Reduced 5HT function is particularly recognized as a vulnerability factor involved in affective disorders, whereas increases in brain 5-HT are found to improve mood and to reduce affective disturbances in healthy and (sub)clinical subjects (Maes and Meltzer 1995; Markus 2003; Markus et al. 1999; Van Praag 2004).

Since 5-HT is synthesized from the essential amino acid tryptophan (TRP), dietary manipulation of plasma TRP has been developed as a method to influence brain 5-HT synthesis. A significant increase in brain tryptophan and 5-HT can be accomplished by the intake of pure tryptophan, by increasing carbohydrate intake, or by consumption of tryptophan-rich alpha-lactalbumin protein. These manipu- 
lations increase plasma concentrations of tryptophan to the sum of the other large neutral amino acids (TRP/LNAA ratio) and give tryptophan the advantage in competition for access into the brain (Curzon 1985; Fernstrom et al. 1973; Fernstrom and Wurtman 1971). These dietary effects on the plasma TRP/LNAA ratio have been demonstrated frequently (Lieberman et al. 1986; Markus 2007; Markus et al. 1998; Rosenthal et al. 1989) and clear associations have been found between plasma TRP/LNAA and brain 5-HT in animal as well as human studies after tryptophan depletion (Biggio et al. 1974; Carpenter et al. 1998; Nishizawa et al. 1997; Williams et al. 1999) and tryptophan challenge (Fernstrom and Wurtman 1971; Markus et al. 2000; Orosco et al. 2004).

Although these dietary methods may seem to be useful to improve 5-HT-related affective functioning by increasing brain 5-HT, their effects seem to be rather modest. Hence, a $20-25 \%$ increase in plasma TRP/LNAA as found with carbohydrate-rich diets does not seem to be sufficient enough to initiate meaningful behavioral changes (Markus et al. 1999; Markus et al. 1998). In addition, only modest effects of carbohydrates on mood are almost exclusively found in affected or subclinical subjects, whereas these effects are rather inconsistent or missing in healthy subjects (Markus 2003).

Supplementing food with pure tryptophan is in many cases limited by regulatory restrictions. However, the use of alpha-lactalbumin (ALAC) was recently introduced as a dietary method to further increase brain 5-HT and improve cognitive-affective behavior. ALAC is a whey-derived protein that contains a higher tryptophan content than most food protein sources (Heine et al. 1996). Recent studies reveal $50-130 \%$ increases in plasma TRP/LNAA after ALAC intake (Booij et al. 2006; Markus et al. 2005; Markus et al. 2000; Merens et al. 2005; Orosco et al. 2004; Scrutton et al. 2007). This TRP/LNAA increase improves brain 5-HT function (Markus et al. 2000; Orosco et al. 2004) and mood- or stress-related affective behavior (Markus et al. 2000). It even reduces sleep disturbances in rats (Minet-Ringuet et al. 2004) and causes sleep-related improvement in behavioral and brain measures of concentration in human subjects (Markus et al. 2005). Using ALAC has a clear nutritional advantage over pure tryptophan and carbohydrates and can also be given for a longer period of time through daily consumption. Nevertheless, the beneficial effects of ALAC on cognitive-affective behavior remain to be rather modest and are not always clearly found (Merens et al. 2005). It may be that the increase in plasma TRP/LNAA by ALAC is too small to cause meaningful behavioral changes. Instead of using intact ALAC protein, hydrolyzed protein with a TRP/ LNAA ratio superior to ALAC or other food sources of TRP may lead to faster and greater increases in plasma
TRP/LNAA and may, therefore, also cause faster and stronger increases in brain 5-HT and affective changes.

The aim of the present study was to investigate the effects on plasma TRP/LNAA ratio and mood after consumption of hydrolyzed protein (HPROT) compared to other sources of tryptophan by healthy volunteers. During five experimental sessions, plasma amino acid concentrations were measured before and several times after intake of intact ALAC, HPROT, and placebo protein, as well as after pure tryptophan and a tryptophan-containing synthetic peptide as positive controls. In addition, mood was measured before and after intake. All of the interventions (except the placebo) contained similar amounts of TRP, but differed in their content of other amino acids.

\section{Materials and methods}

\section{Subjects}

Eighteen healthy students (nine men and nine women aged between 18 and 30 years) at Maastricht University participated in the study. Exclusion criteria for participation were chronic and current illness; history of psychiatric or medical illness; medication use; metabolic, hormonal, or intestinal diseases; irregular diets or deviant eating habits; excessive use of alcohol ( $>2 \mathrm{U} /$ day), cigarettes, coffee, and/ or drugs; aversion for sugar-rich products; pregnancy; and any discomfort with blood drawing procedures as assessed by health and lifestyle questionnaires. Subjects participating in the experiment had a body mass index in the normal range (BMI in $\mathrm{kg} / \mathrm{m}^{2}$ between 20 and 25), and female subjects were matched for contraception. Women participated during their mid-late follicular phase (day 4-10), while women using contraception participated when they actually used the contraception pill. All subjects that participated in the experiment were nonsmokers and nondrug users and were not allowed to drink alcohol starting 2 days before the experiment until the end of the experiment. The study was approved by the Medical Ethics Committee (MEC 06-3-029) of the Academic Hospital Maastricht (Maastricht, The Netherlands), and the procedures followed were in accordance with the Helsinki Declaration of 1975 as revised in 1983. All subjects gave their signed informed consent to participate in the experiment prior to their inclusion in the experiment and received a financial compensation for their participation.

Procedure

Approximately 600 students at Maastricht University received written information about the study and an invitation to participate. In addition, students who were 
interested to participate were requested to complete and return a questionnaire package concerning general information (health, smoking and drinking habits, caffeine consumption, weight and height, and use of psychoactive drugs) and several questionnaires concerning psychopathology (mood disorders, family history of depression, medical complaints, etc.). From the subjects showing interest in taking part in the experiment, 18 healthy subjects were selected for the experiment. Subsequently, subjects taking part in the experiment were invited at the laboratory to receive information about the study and to become familiar with the environment and experimental procedures.

During five experimental morning sessions, subjects visited the laboratory to monitor plasma TRP/LNAA concentrations and mood following intake of a drink containing different TRP/LNAA ratios (see the "Diets" section). The order of presentation of dietary conditions was counterbalanced, and the five experimental days were separated by a 1 -week period. Before and 15, 30, 60, 90 120, 180, and 210 min after ingestion, blood samples were taken to measure the dose-dependent effect (response curve) of the different tryptophan or protein sources on plasma amino acid concentrations and the TRP/LNAA ratio. In addition, mood was measured before, $60 \mathrm{~min}$, and 210 min after intake (Fig. 1).

On each experimental morning, six subjects arrived at the laboratory at 8:30 A.M. Subjects had been instructed to fast overnight; only water or tea without sugar was permitted. In addition, subjects were not allowed to use any kind of drugs before and during the experiment (see selection criteria) or to drink alcohol the day before their participation and arrival at the laboratory. After arrival, subjects were allowed to rest for a while before an indwelling catheter was inserted in their nonpreferred forearm. Then all subjects were brought into a laboratory room containing sitting areas with separated computer systems. Each subject was separately seated in front of his or her personal computer screen and instructed about the experiment. Subsequently, subjects were exposed to a computerized version of the profile of mood state (POMS) (for detailed description, see below). After the first test session, subjects received a test drink containing different TRP/LNAA ratios. Before, $60 \mathrm{~min}$, and $210 \mathrm{~min}$ after intake, respectively, a first, second, and third mood measure was conducted. Before and 15, 30, 60, 90 120, 180, and $210 \mathrm{~min}$ after intake, blood samples were taken to measure the dietary effects on plasma amino acid concentrations. Between measurements, all subjects stayed in the laboratory room to read or work on their own private computer.

\section{Diets}

On each experimental morning, a 312-ml drink was consumed containing different tryptophan (TRP) or LNAA concentrations. The reference condition included $20 \mathrm{~g}$ casein protein (PLC: DSM, Delft, The Netherlands) with $0.4 \mathrm{~g}$ TRP and $10 \mathrm{~g}$ LNAA, whereas the test conditions included $15 \mathrm{~g}$ intact alpha-lactalbumin (ALAC) whey protein (BioPURE, Davisco Foods International, USA) with $0.8 \mathrm{~g}$ TRP and $9.4 \mathrm{~g}$ LNAA, protein hydrolysate or HPROT (PeptoBalance ${ }^{\mathrm{TM}}$ : DSM, Delft, The Netherlands) with $0.8 \mathrm{~g}$ TRP and $4 \mathrm{~g}$ LNAA, $0.8 \mathrm{~g}$ pure tryptophan

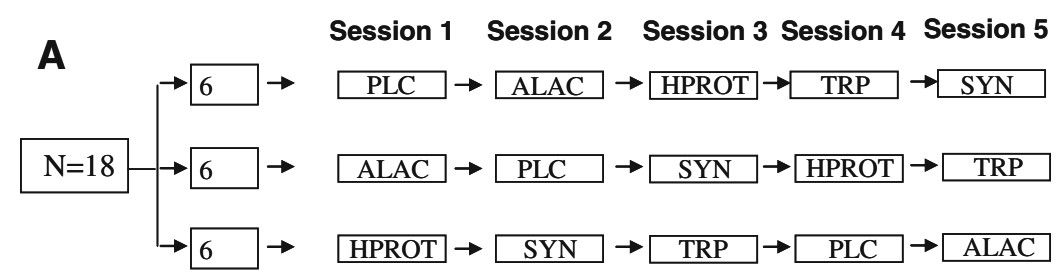

B

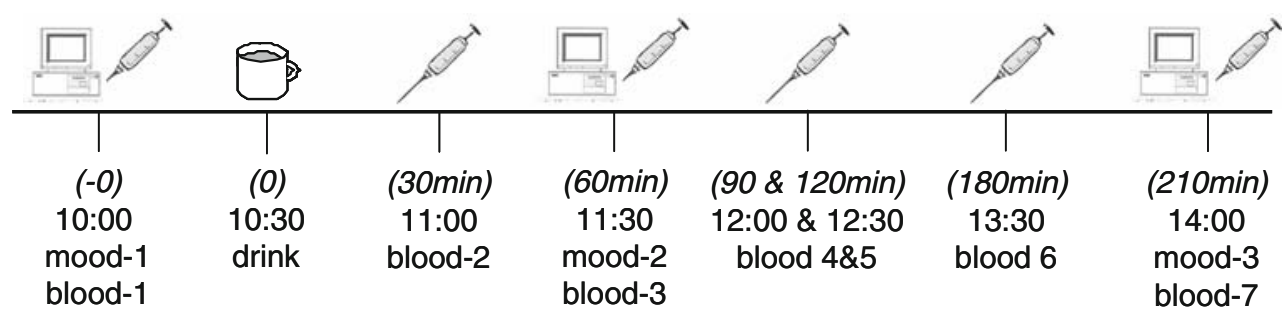

Fig. 1 General design (a) and time schedule (a) of the experiment. a During five experimental sessions, 18 subjects received protein and peptide sources with different TRP and LNAA concentrations. Order of treatment was balanced between three groups. b During each experimental session, subjects received the protein or peptide source after a baseline mood and blood measure. Before, $60 \mathrm{~min}$, and 210 min after intake, mood was measured. Before and 30, 60, 90, 120, 180 , and $210 \mathrm{~min}$ after intake, plasma samples were taken for amino acid assessment 
(TRP: Orthica, Almere, The Netherlands) and $1.2 \mathrm{~g}$ synthetic peptide (SYN: Ser-TRP, DSM, Delft; Molecular formula $\mathrm{C}_{14} \mathrm{H}_{17} \mathrm{~N}_{3} \mathrm{O}_{4}$ ) containing $0.8 \mathrm{~g}$ tryptophan (Tables 1 and 2).

All drinks are prepared by mixing the powder with $0.10 \mathrm{~g}$ sweetener (acesulfame) and were filled up by plain water in order to reach a 312-ml drink. Research assistants blind to the dietary conditions conducted the administration of the different drinks.

\section{Measurements}

\section{Profile of mood states}

Changes in mood are measured using a computerized Dutch shortened version of the POMS questionnaire (Wald and Mellenbergh 1990) as a visual analogue scale ranging from "strongly disagree" to "strongly agree." The POMS was calculated by the total mood scores on five different subscales, ranging from anger, depression, fatigue, and tension that refer to a negative mood state to vigor concerning a positive mood.

\section{Biochemical analyses}

Blood samples were collected in duplicate in $5 \mathrm{ml}$ vacutainer tubes containing sodium heparin and centrifuged at $5,000 \mathrm{rpm}$ for $5 \mathrm{~min}$ at $4^{\circ} \mathrm{C}$. Subsequently, the supernatants were directly stored at $-80^{\circ} \mathrm{C}$ until analysis. Before storage, the supernatant $(100 \mu \mathrm{l})$ was mixed with $4 \mathrm{mg}$ sulfasalicyl acid. Plasma amino acid analysis was conducted with high-pressure liquid chromatography (HPLC), making use of a 2- to 3- $\mu \mathrm{m}$ Bischof Spherisorb ODS II column. The plasma tryptophan ratio was calculated by dividing the plasma tryptophan concentration (in $\mu \mathrm{mol} / \mathrm{L}$ ) by the sum of the other large neutral amino acids, i.e., valine, isoleucine, leucine, tyrosine, and phenylalanine.

Table 1 Composition of the standard protein (PLC), alpha-lactalbumin whey protein (ALAC), protein hydrolysate (HPROT), pure tryptophan (TRP), and synthetic dipeptide (SYN) condition

\begin{tabular}{llll}
\hline Source & Product $(\mathrm{g})$ & TRP $(\mathrm{g})$ & $\begin{array}{l}\text { TRP/LNAA } \\
(\mathrm{mol} / \mathrm{mol})\end{array}$ \\
\hline PLC & $20 \mathrm{~g} / 312 \mathrm{ml}$ & 0.4 & 0.04 \\
ALAC & $15 \mathrm{~g} / 312 \mathrm{ml}$ & 0.8 & 0.1 \\
HPROT & $312 \mathrm{ml}$ & 0.8 & 1.1 \\
TRP & $0.8 \mathrm{~g} / 312 \mathrm{ml}$ & 0.8 & $\infty$ \\
SYN & $1.2 \mathrm{~g} / 312 \mathrm{ml}$ & 0.8 & $\infty$ \\
\hline
\end{tabular}

Table 2 Amino acid profile

\begin{tabular}{lccc}
\hline Amino acid profile $(\mathrm{g})$ & HPROT & PLC & ALAC \\
\hline Isoleucine & 1.004 & 1.800 & 2.012 \\
Leucine & 0.745 & 2.733 & 3.306 \\
Phenylalanine & 0.480 & 1.467 & 1.309 \\
Tyrosine & 1.216 & 1.867 & 1.451 \\
Valine & 0.554 & 2.133 & 1.322 \\
Tryptophan & 0.8 & 0.4 & 0.8 \\
Total & 3.999 & 10 & 9.4 \\
\hline
\end{tabular}

Experimental design and statistical analysis

The main research questions formulated in the introduction were analyzed by means of repeated-measures multivariate and univariate analyses of variance (MANOVA and ANOVA) by using the general linear model (GLM; SPSS 12.0 for Windows) with one within-subjects factors "condition" (five different conditions: PLC, ALAC, HPROT, TRP, SYN) on the several dependent measures from mood and plasma amino acids. Although we already counterbalanced for order of condition, this variable was preliminarily taken as a between-subjects factor. Yet, because order of intervention did not contribute to any of the results, final analyses were performed with only condition as a within-subjects factor. For the effect of diet manipulation on blood samples, repeated-measures MANOVA was performed with first- and second-order polynomial contrasts. Only significant results revealed by these procedures were further examined by univariate tests. Huynh-Feldt or Greenhouse-Geisser corrected $P$ values, their corresponding epsilons, as well as the original, i.e., uncorrected, degrees of freedom are reported when the sphericity assumption was not met. The study, including validation of the group size, was designed to detect a large effect size $\left(\mu^{2} 0.20\right)$ for a power of 0.80 at alpha $=0.05$ (requiring a group size of at least 17 subjects). All statistics were evaluated at a significance level of $5 \%$. Data are reported as the means $\pm \mathrm{SD}$.

\section{Results}

\section{Plasma TRP/LNAA}

A first repeated-measures ANOVA with condition (PLC, ALAC, HPROT, TRP, SYN) and time $(0,30,60,90,120$, 180 , and $210 \mathrm{~min}$ ) as within-subjects factors on the plasma TRP/LNAA ratio revealed a main significant effect of time $[F(6,90)=122 ; P<0.0001]$ and condition $[F(4,60)=79,68$; $P<0.0001]$ and a significant interaction between condition and time $[F(24,360)=41,50 ; P<0.0001]$, indicating that the 
increase in plasma TRP/LNAA ratio across time differed between conditions. As shown in Fig. 2, the highest significant increases in plasma TRP/LNAA ratio were found 30-120 min after SYN $[F(6,96)=87,89 ; P<0.0001]$ and HPROT $[F(6,90)=86,54 ; P<0.0001]$. There were no significant differences in peak TRP/LNAA responses between these two conditions with the exception that peak (263\%) increases in TRP/LNAA after SYN appeared significantly faster (after $60 \mathrm{~min}$ ) than peak $(255 \%)$ increases after HPROT (after $90 \mathrm{~min}$ ) $[F(3,14)=3,66$; $P=0.04]$. The increase in TRP/LNAA after HPROT and SYN was significantly faster and higher than after TRP $[F(4,60)=4,56 ; P=0.003]$. With TRP, a peak $191 \%$ increase in TRP/LNAA was found 120 min after intake $(P<0.0001)$. A significant increase in plasma TRP/LNAA was also found $60-210 \mathrm{~min}$ after ALAC $[F(6,96)=72 ; P<0.0001]$ with a peak $67 \%$ increase $120 \mathrm{~min}$ after intake $(P<0.0001)$, but this was significantly lower compared with HPROT $[F(4,60)=60,4 ; P<0.0001]$ and TRP $[F(4,64)=30,83$; $P<0.0001]$. After PLC, there was a significant decline in TRP/LNAA starting $60 \mathrm{~min}(-27 \%)$ until $210 \mathrm{~min}(<0.001)$ after intake $[F(6,96)=32,95 ; P<0.0001]$. The amino acid concentrations of the different protein and peptide sources across time are given in Table 3 and the plasma TRP/ LNAA ratios of different conditions across time are given in Table 4.

\section{Trp/LNAA}

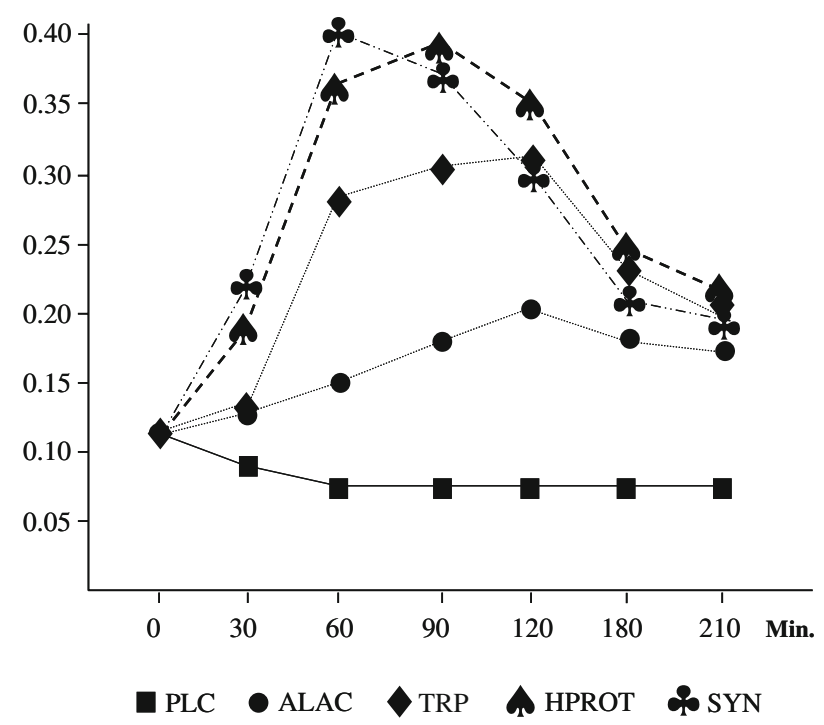

Fig. 2 Mean changes in plasma tryptophan compared with the other large neutral amino acids ratio (TRP/LNAA) after intake of hydrolyzed protein $(H P R O T)$, alpha-lactalbumin $(A L A C)$, casein protein $(P L C)$, pure tryptophan $(T R P)$, and tryptophan-containing synthetic peptide $(S Y N)$. A multivariate significant interaction of condition by time $[P<0.0001]$ revealed the highest and fastest significant increases in plasma TRP/LNAA ratio 30-120 min after SYN $[P<0.0001]$ and HPROT $[P<0.0001]$
Mood

Repeated-measures ANOVA with condition (PLC, ALAC, HPROT, TRP, SYN) and time (0, 60, and $210 \mathrm{~min})$ as within-subjects factors on the total mood scores revealed a significant effect of time $[F(2,32)=3,27 ; P<0.05]$ and a significant interaction of condition $\times$ time $[F(4,64)=3,68$; $P=0.009]$, indicating that mood changes across time significantly differed between conditions. As shown in Fig. 3, comparable improvements of mood were found $60 \mathrm{~min}$ after HPROT $(P=0.015)$ and TRP $(P=0.010)$ but only after HPROT mood further improved $210 \mathrm{~min}$ after intake compared with TRP $(P=0.04)$. In contrast, no mood changes were found after PLC $(P>0.2)$ and ALAC $(P=0.2)$. Although mood also seem to improve after SYN, this was not significant $(P>0.2)$.

\section{Conclusion}

The aim of the present study was to investigate whether a protein hydrolysate (HPROT) has a greater effect on temporal increases in plasma TRP/LNAA and mood compared with intact alpha-lactalbumin (ALAC) protein in healthy volunteers. In addition, a tryptophan-containing synthetic peptide (SYN) and pure tryptophan (TRP) were included as positive controls. Significantly faster and greater increases in plasma TRP/LNAA where found after HPROT intake than after intake of ALAC. In addition, the effects of HPROT on plasma TRP/LNAA were comparable with the effects of the tryptophan-containing synthetic dipeptide and even exceeded the effect of pure tryptophan (TRP). Mood improved after HPROT and TRP $60 \mathrm{~min}$ after intake, and the most profound and durable mood improving effects were found with HPROT 210 min after intake.

\section{Effects on plasma TRP/LNAA}

In general, the changes of the TRP/LNAA ratios were consistent with the kinetics of TRP concentrations reported earlier (Domino 1976; Yuwiler et al. 1981). There was a significantly greater increase in plasma TRP/LNAA after intake of the protein hydrolysate HPROT (255\%) compared with intact whey protein ALAC (67\%). This effect of HPROT on plasma TRP/LNAA was comparable with the tryptophan-containing synthetic peptide (SYN) and even largely exceeded the $191 \%$ increase in plasma TRP/LNAA induced by pure tryptophan. Since all sources (except the negative control) contained equal amounts of TRP, it was anticipated that the differences found in plasma TRP/ LNAA ratios should be due primarily to differences in LNAA content between the sources. Whereas this notion is substantiated by the results from the natural TRP sources, 
Table 3 Plasma amino acid concentrations $(\mu \mathrm{m} / \mathrm{L}$ ) across time after protein (PLC), alpha-lactalbumin protein (ALAC), protein hydrolysate (HPROT), pure tryptophan (TRP), and synthetic dipeptide (SYN)

\begin{tabular}{|c|c|c|c|c|c|c|c|c|}
\hline \multirow[t]{2}{*}{ Amino acid } & \multirow[t]{2}{*}{ Condition } & \multicolumn{7}{|c|}{ Time (min) } \\
\hline & & 0 & 30 & 60 & 90 & 120 & 180 & 210 \\
\hline \multirow[t]{5}{*}{ Isoleucine } & PLC & 0.07 & 0.10 & 0.18 & 0.15 & 0.12 & 0.09 & 0.08 \\
\hline & ALAC & 0.08 & 0.12 & 0.20 & 0.22 & 0.18 & 0.12 & 0.11 \\
\hline & HPROT & 0.07 & 0.09 & 0.09 & 0.14 & 0.09 & 0.08 & 0.09 \\
\hline & TRP & 0.07 & 0.07 & 0.07 & 0.06 & 0.07 & 0.07 & 0.07 \\
\hline & SYN & 0.06 & 0.07 & 0.06 & 0.06 & 0.06 & 0.06 & 0.07 \\
\hline \multirow[t]{5}{*}{ Leucine } & PLC & 0.12 & 0.19 & 0.31 & 0.26 & 0.22 & 0.17 & 0.16 \\
\hline & ALAC & 0.13 & 0.22 & 0.37 & 0.38 & 0.28 & 0.21 & 0.20 \\
\hline & HPROT & 0.13 & 0.14 & 0.14 & 0.13 & 0.13 & 0.13 & 0.14 \\
\hline & TRP & 0.13 & 0.13 & 0.12 & 0.12 & 0.12 & 0.12 & 0.13 \\
\hline & SYN & 0.11 & 0.14 & 0.12 & 0.12 & 0.12 & 0.12 & 0.13 \\
\hline \multirow[t]{5}{*}{ Phenylalanine } & PLC & 0.06 & 0.08 & 0.10 & 0.08 & 0.08 & 0.06 & 0.06 \\
\hline & ALAC & 0.07 & 0.09 & 0.11 & 0.10 & 0.09 & 0.07 & 0.07 \\
\hline & HPROT & 0.07 & 0.07 & 0.07 & 0.06 & 0.10 & 0.06 & 0.07 \\
\hline & TRP & 0.07 & 0.07 & 0.06 & 0.06 & 0.06 & 0.06 & 0.06 \\
\hline & SYN & 0.06 & 0.07 & 0.06 & 0.06 & 0.06 & 0.06 & 0.06 \\
\hline \multirow[t]{5}{*}{ Tyrosine } & PLC & 0.06 & 0.07 & 0.12 & 0.11 & 0.09 & 0.07 & 0.07 \\
\hline & ALAC & 0.06 & 0.08 & 0.12 & 0.12 & 0.10 & 0.08 & 0.08 \\
\hline & HPROT & 0.06 & 0.07 & 0.07 & 0.06 & 0.06 & 0.06 & 0.06 \\
\hline & TRP & 0.06 & 0.06 & 0.06 & 0.05 & 0.06 & 0.05 & 0.05 \\
\hline & SYN & 0.05 & 0.06 & 0.05 & 0.05 & 0.05 & 0.05 & 0.05 \\
\hline \multirow[t]{5}{*}{ Valine } & PLC & 0.24 & 0.28 & 0.45 & 0.42 & 0.38 & 0.32 & 0.30 \\
\hline & ALAC & 0.26 & 0.30 & 0.38 & 0.42 & 0.35 & 0.29 & 0.28 \\
\hline & HPROT & 0.26 & 0.27 & 0.25 & 0.25 & 0.25 & 0.25 & 0.26 \\
\hline & TRP & 0.25 & 0.25 & 0.23 & 0.22 & 0.23 & 0.22 & 0.23 \\
\hline & SYN & 0.21 & 0.26 & 0.22 & 0.22 & 0.22 & 0.21 & 0.23 \\
\hline \multirow[t]{5}{*}{ Tryptophan } & PLC & 0.06 & 0.07 & 0.08 & 0.08 & 0.07 & 0.06 & 0.05 \\
\hline & ALAC & 0.07 & 0.09 & 0.18 & 0.23 & 0.19 & 0.13 & 0.12 \\
\hline & HPROT & 0.07 & 0.13 & 0.21 & 0.23 & 0.20 & 0.14 & 0.13 \\
\hline & TRP & 0.07 & 0.07 & 0.17 & 0.18 & 0.18 & 0.13 & 0.11 \\
\hline & SYN & 0.06 & 0.13 & 0.21 & 0.18 & 0.15 & 0.11 & 0.10 \\
\hline
\end{tabular}

the findings on pure TRP and the synthetic dipeptide show that other factors may play a role as well. Both pure TRP and SYN have an infinitely high TRP/LNAA ratio, but synthetic dipeptide results in a substantially higher plasma TRP/LNAA ratio than pure TRP. We speculate that TRP in the form of small peptides has a better bioavailability than pure TRP as such. It has been suggested that a $40-70 \%$ variation in plasma TRP/LNAA could be sufficient to change brain 5-HT content in animal as well as human, either reducing brain 5-HT by lowering plasma TRP/LNAA after tryptophan depletion (Biggio et al. 1974; Carpenter et al. 1998; Nishizawa et al. 1997; Williams et al. 1999) and

Table 4 Plasma TRP/LNAA ratios ( $\mu \mathrm{m} / \mathrm{L}$ ) across time after protein (PLC), alpha-lactalbumin protein (ALAC), protein hydrolysate (HPROT), pure tryptophan (TRP), and synthetic dipeptide (SYN)

\begin{tabular}{|c|c|c|c|c|c|c|c|c|}
\hline \multirow[t]{2}{*}{ Plasma ratio } & \multirow[t]{2}{*}{ Condition } & \multicolumn{7}{|c|}{ Time (min) } \\
\hline & & 0 & 30 & 60 & 90 & 120 & 180 & 210 \\
\hline \multirow[t]{5}{*}{ TRP/LNAA } & PLC & 0.11 & 0.09 & 0.08 & 0.08 & 0.08 & 0.08 & 0.08 \\
\hline & ALAC & 0.12 & 0.12 & 0.15 & 0.18 & 0.2 & 0.18 & 0.17 \\
\hline & HPROT & 0.11 & 0.19 & 0.36 & 0.39 & 0.35 & 0.25 & 0.22 \\
\hline & TRP & 0.11 & 0.12 & 0.29 & 0.31 & 0.32 & 0.24 & 0.20 \\
\hline & SYN & 0.11 & 0.22 & 0.40 & 0.37 & 0.31 & 0.22 & 0.19 \\
\hline
\end{tabular}




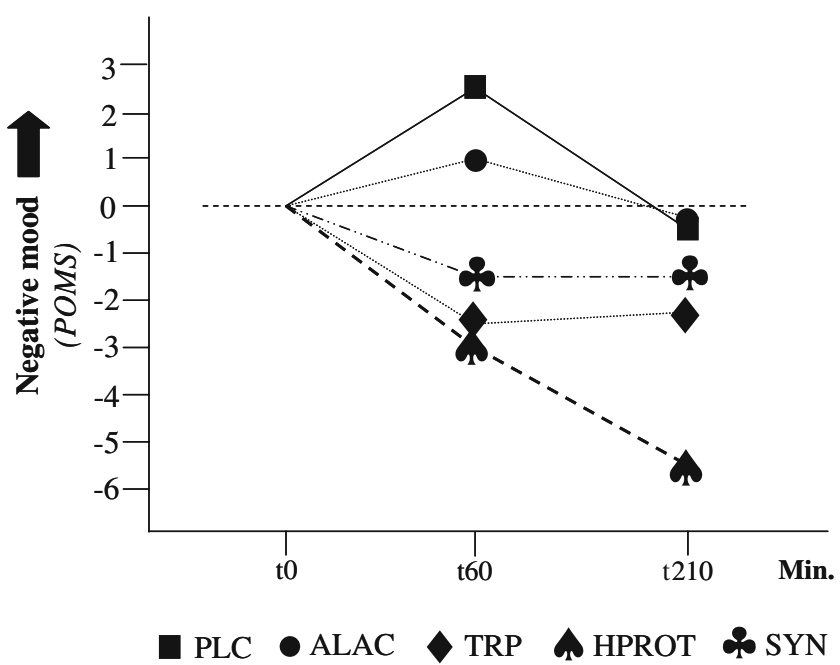

Fig. 3 Mean differences in the total mood changes of the POMS after intake of hydrolyzed protein (HPROT), alpha-lactalbumin ( $A L A C)$, casein protein $(P L C)$, pure tryptophan $(T R P)$, and tryptophan-containing synthetic peptide $(S Y N)$. A significant interaction of condition by time $[P=0.009]$ indicated comparable mood improvements $60 \mathrm{~min}$ after HPROT $(P=015)$ and TRP $(P=0.010)$ with the most durable mood improvements following HPROT $210 \mathrm{~min}$ after intake $(P=0.04)$

increasing 5-HT by enhancing plasma TRP/LNAA after tryptophan challenge (Fernstrom and Wurtman 1971; Markus et al. 2000; Orosco et al. 2004) or increasing carbohydrates in normal meals (Wurtman et al. 2003). Since the current $255 \%$ rise in TRP/LNAA induced by consumption of hydrolyzed protein (HPROT) largely exceeds this threshold and also based on findings that tryptophan suppletion affected mood and behavior in human (Markus et al. 2000; for review, see Markus 2008), it is very likely that this causes a much greater rise in available brain TRP and 5-HT and a subsequent stronger psychological-emotional effect in the brain.

A significant improvement in mood was found $1 \mathrm{~h}$ after consumption of the protein hydrolysate (HPROT) and intake of pure L-tryptophan. Moreover, only HPROT was able to induce a sustained mood improvement until $210 \mathrm{~min}$ after intake. No significant effects were found with intact whey protein (ALAC) or the synthetic tryptophan dipeptide. The absence of a mood effect after consumption of ALAC is comparable with previous studies, showing that ALAC only induces beneficial effects on mood in stressvulnerable subjects under acute stress exposure (Markus 2003; Markus et al. 2000). Current results suggest that a large $255 \%$ increase in plasma TRP/LNAA may be sufficient to improve baseline mood in nonvulnerable subjects as well. Nevertheless, the effects of HPROT may still be more profound in serotonin-vulnerably subjects and/ or when brain tryptophan supply is actually required. People differ in their sensitivity to alterations in the serotonergic system, and among the different factors involved in such brain serotonin vulnerabilities, genetic proneness and chronically stressful circumstances are the most frequently described (Firk and Markus 2007; Jans et al. 2007; Markus 2003; Markus et al. 2000). Thus, most beneficial effects of brain tryptophan supply may be expected in "serotonin-vulnerable" subjects like people with a family history of depression, carrying the susceptible short-allele serotonin transporter gene (5-HTTLPR), in chronically stressed subjects (Firk and Markus 2007; Jans et al. 2007; Markus 2003; Markus et al. 2000), or in clinically depressed or remitted subjects who respond to selective serotonin reuptake inhibitors. This intriguing hypothesis certainly deserves further investigation.

Contrary to our expectations, there were no significant improvements in mood after intake of a tryptophancontaining synthetic peptide (SYN). Although mood tended to be improved after SYN compared with PLC and ALAC, this effect was not statistically significant. This is surprising since the increase in plasma TRP/LNAA following intake of SYN was comparable to the increase found after consumption of HPROT and even exceeded the 191\% increase in plasma TRP/LNAA as found after pure tryptophan. Although hypothetically, it may be that the brain bioavailability of tryptophan released from a synthetic dipeptide is somehow reduced. Alternatively, the power of the current study may not have been sufficient to detect a significant difference in the SYN condition.

Current findings support the assumption that the use of a hydrolyzed protein may be a more adequate method to increase central tryptophan and serotonin levels and brain function compared to intact alpha-lactalbumin or pure tryptophan and, hence, to further improve serotonin-related affective behavior. Although the beneficial affective effects of tryptophan supply appear to be rather negligible in healthy subjects under normal circumstances, it is anticipated that the effects of the current hydrolyzed protein may become more vivid when chronically administered, under high affecting circumstances that require enhanced tryptophan supply, and in clinically or serotonin-vulnerable subjects who are responsive to brain serotonin manipulations. This should be explored in future research.

Acknowledgements CRM was the principle investigator who designed the study and was responsible for the conduction of the study, the data analysis, and the writing of the manuscript. CF reviewed the manuscript. GJFS, CG, and JK are employed at DSM Food Specialties B.V., The Netherlands and provided the test proteins and reviewed the final version of the manuscript. The study was approved by the Medical Ethics Committee of the Academic Hospital Maastricht (Maastricht, The Netherlands) and comply with the Helsinki Declaration of 1975 (as revised in 1983) and with the current laws of The Netherlands. The study was supported by a grant from DSM Food Specialties B.V., The Netherlands. 
Open Access This article is distributed under the terms of the Creative Commons Attribution Noncommercial License which permits any noncommercial use, distribution, and reproduction in any medium, provided the original author(s) and source are credited.

\section{References}

Biggio G, Fadda F, Fanni P, Tagliamonte A, Gessa GL (1974) Rapid depletion of serum tryptophan, brain tryptophan, serotonin and 5hydroxyindoleacetic acid by a tryptophan-free diet. Life Sci 14:1321-1329

Booij L, Merens W, Markus CR, Van der Does AJ (2006) Diet rich in \{alpha\}-lactalbumin improves memory in unmedicated recovered depressed patients and matched controls. J Psychopharmacol 20:526-535

Carpenter LL, Anderson GM, Pelton GH, Gudin JA, Kirwin PD, Price LH et al (1998) Tryptophan depletion during continuous CSF sampling in healthy human subjects. Neuropsychopharmacology 19:26-35

Curzon G (1985) Effects of food intake on brain transmitter amine precursors and amine synthesis. In: Sandler M, Silverstone T (eds) Psychopharmacology and food. Oxford University Press, Oxford, pp 59-70

Domino EF (1976) Pharmacokinetics of oral tryptophan in drug-free psychistric patients. In: Gottschalk LA, Merkis E (eds) Pharmacokinetics of psychoactive drugs. Spektrum, New York, pp 117-126

Fernstrom JD, Wurtman RJ (1971) Brain serotonin content: physiological dependence on plasma tryptophan levels. Science 173:149-152

Fernstrom JD, Larin F, Wurtman RJ (1973) Correlations between brain tryptophan and plasma neutral amino acids levels following food consumption in rats. Life Sci 13:517

Firk C, Markus CR (2007) Review: serotonin by stress interaction: a susceptibility factor for the development of depression? J Psychopharmacol 21:538-544

Heine W, Radke M, Wutzke KD, Peters E, Kundt G (1996) Alphalactalbumin-enriched low-protein infant formulas: a comparison to breast milk feeding. Acta Paediatr 85:1024-1028

Jans LA, Riedel WJ, Markus CR, Blokland A (2007) Serotonergic vulnerability and depression: assumptions, experimental evidence and implications. Mol Psychiatry 12:522-543

Lieberman HR, Wurtman JJ, Chew B (1986) Changes in mood after carbohydrate consumption among obese individuals. Am J Clin Nutr 44:772-778

Maes M, Meltzer HY (1995) The serotonin hypothesis of major depression. In: Bloom FE, Kupfer DJ (eds) Psychopharmacology: the fourth generation of progress. Raven, New York, pp 933-944

Markus CR (2003) Food, stress and mood. In: Wadson D, Dodds F (eds) Performance functional foods. Woodhead, Cambridge

Markus CR (2007) Effects of carbohydrates on brain tryptophan availability and stress performance. Biol Psychol 76:83-90

Markus CR (2008) Dietary amino acids and brain 5-HT function; implications for stress and stress-related affective changes. Neuromolecular Med (in press)

Markus CR, Panhuysen G, Tuiten A, Koppeschaar H, Fekkes D, Peters ML (1998) Does carbohydrate-rich, protein-poor food prevent a deterioration of mood and cognitive performance of stress-prone subjects when subjected to a stressful task? Appetite 31:49-65

Markus CR, Panhuysen G, Jonkman LM, Bachman M (1999) Carbohydrate intake improves cognitive performance of stressprone individuals under controllable laboratory stress. Br J Nutr $82: 457-467$

Markus CR, Olivier B, Panhuysen GE, Van Der Gugten J, Alles MS, Tuiten A, Westenberg HG, Fekkes D, Koppeschaar HF, de Haan EE (2000) The bovine protein alpha-lactalbumin increases the plasma ratio of tryptophan to the other large neutral amino acids, and in vulnerable subjects raises brain serotonin activity, reduces cortisol concentration, and improves mood under stress. Am J Clin Nutr 71:1536-1544

Markus CR, Jonkman LM, Lammers JH, Deutz NE, Messer MH, Rigtering N (2005) Evening intake of alpha-lactalbumin increases plasma tryptophan availability and improves morning alertness and brain measures of attention. Am J Clin Nutr 81:1026-1033

Merens W, Booij L, Markus R, Zitman FG, Onkenhout W, Van der Does AJ (2005) The effects of a diet enriched with alphalactalbumin on mood and cortisol response in unmedicated recovered depressed subjects and controls. Br J Nutr 94:415-422

Minet-Ringuet J, Le Ruyet PM, Tome D, Even PC (2004) A tryptophan-rich protein diet efficiently restores sleep after food deprivation in the rat. Behav Brain Res 152:335-340

Nishizawa S, Benkelfat C, Young SN, Leyton M, Mzengeza S, de Montigny C et al (1997) Differences between males and females in rates of serotonin synthesis in human brain. Proc Natl Acad Sci 94:5308-5313

Orosco M, Rouch C, Beslot F, Feurte S, Regnault A, Dauge V (2004) Alpha-lactalbumin-enriched diets enhance serotonin release and induce anxiolytic and rewarding effects in the rat. Behav Brain Res 148:1-10

Rosenthal NE, Genhart MJ, Caballero B, Jacobsen FM, Skwerer RG, Coursey RD, Rogers S, Spring BJ (1989) Psychobiological effects of carbohydrate- and protein-rich meals in patients with seasonal affective disorder and normal controls. Biol Psychiatry 25:1029-40

Scrutton H, Carbonnier A, Cowen PJ, Harmer C (2007) Effects of \{alpha\}-lactalbumin on emotional processing in healthy women. J Psychopharmacol 21:519-524

Van Praag HM (2004) Can stress cause depression? Prog Neuropsychopharmacol Biol Psychiatry 28:891-907

Wald FDM, Mellenbergh GJ (1990) De verkorte versie van de Nederlandse vertaling van de Profile of Mood States (POMS). Ned Tijdschr Psychol Haar Grensgeb 45:86-90

Williams WA, Shoaf SE, Hommer D, Rawlings R, Linnoila M (1999) Effects of acute tryptophan depletion on plasma and cerebrospinal fluid tryptophan and 5-hydroxyindoleacetic acid in normal volunteers. J Neurochem 72:1641-1647

Wurtman RJ, Wurtman JJ, Regan MM, McDermott JM, Tsay RH, Breu JJ (2003) Effects of normal meals rich in carbohydrates or proteins on plasma tryptophan and tyrosine ratios. Am J Clin Nutr 77:128-132

Yuwiler A, Brammer GL, Morley JE, Raleigh MJ, Flannery JW, Geller E (1981) Short-term and repetitive administration of oral tryptophan in normal men. Effects on blood tryptophan, serotonin, and kynurenine concentrations. Arch Gen Psychiatry $38: 619-626$ 